\title{
Cannabinoid-1 receptor antagonists in type-2 diabetes
}

\author{
André J. Scheen MD, PhD \\ Professor, Doctor \\ Division of Diabetes, Nutrition and Metabolic Disorders, CHU Sart Tilman (B35), University of Liège, B 4000 Liège, Belgium
}

\begin{abstract}
Type-2 diabetes is closely related to abdominal obesity and is generally associated with other cardiometabolic risk factors, resulting in a risk of major cardiovascular disease. Several animal and human observations suggest that the endocannabinoid system is over-active in the presence of abdominal obesity and/or diabetes. Both central and peripheral endocannabinoid actions, via the activation of CB1 receptors, promote weight gain and associated metabolic changes. Rimonabant, the first selective $\mathrm{CB}_{1}$ receptor blocker in clinical use, has been shown to reduce body weight, waist circumference, triglycerides, blood pressure, insulin resistance index and C-reactive protein levels, and to increase high-density lipoprotein (HDL) cholesterol and adiponectin concentrations in both non-diabetic and diabetic overweight/obese patients. In addition, a $0.5-0.7 \%$ reduction in HbA1c levels was observed in metformin- or sulphonylurea-treated patients with type-2 diabetes and in drugnaïve diabetic patients. Almost half of the metabolic changes, including HbA1c reduction, could not be explained by weight loss, suggesting that there are direct peripheral effects. Rimonabant was generally welltolerated, and the safety profile was similar in diabetic and non-diabetic patients, with a higher incidence of depressed mood disorders, nausea and dizziness. In conclusion, the potential role of rimonabant in overweight/obese patients with type- 2 diabetes and at high risk of cardiovascular disease deserves much consideration.
\end{abstract}

Keywords: rimonabant ; obesity ; type-2 diabetes ; cardiovascular risk ; $\mathrm{CB}_{1}$ receptor blocker ; endocannabinoid system.

Type-2 diabetes frequently coexists with a cluster of other cardiovascular and metabolic risk factors - including abdominal obesity, low high-density lipoprotein cholesterol (HDL-C), high triglycerides, elevated blood pressure and silent inflammation - and is considered to be a cardiovascular disease (CVD) risk equivalent. ${ }^{1,2}$

Being overweight or obese - abdominally obese in particular - increases the risk of type-2 diabetes and CVD. ${ }^{3-5}$ Yet individuals with type-2 diabetes often have more difficulty in losing weight and experience weight gain associated with most antidiabetic medications. ${ }^{6,7}$ The treatment of multiple cardiovascular and metabolic riskfactors is central to the management of diabetic patients ${ }^{1,2,5,8,9}$, and the importance of weight management is well recognized in type-2 diabetes. ${ }^{7,10,11}$

Over the last two decades a new biochemical/physiological system, known as the endocannabinoid (EC) system, was discovered. ${ }^{12,13}$ There is considerable evidence that the EC system plays a significant role in appetite drive and associated behaviours, but also in endocrine and metabolic regulation and energy balance. ${ }^{14}$ Indeed, cannabinoid (CB) receptors, especially CB1 receptors, participate in the physiological modulation of many central and peripheral functions. ${ }^{14}$ The tremendous advances in the understanding of the molecular basis of $\mathrm{CB}$ activity ${ }^{15}$ has encouraged many pharmaceutical companies to develop synthetic CB analogues and antagonists, leading to an explosion of basic research and clinical trials. ${ }^{16-18}$ For instance, it is reasonable to hypothesize that attenuation of EC-system over-activity would have therapeutic benefit in treating disorders that might have a component of excessive appetite drive, such as obesity and related disturbances. ${ }^{18-21}$ Interestingly, whereas antagonism of CB1 receptors acutely reduces food intake, the long-term effects on weight reduction and metabolic regulation rather appear to be mediated by stimulation of energy expenditure and by peripheral effects related to adipose tissue, liver, skeletal muscle, and pancreas physiology. ${ }^{14,22}$ Such observations extend the potential use of CB1 antagonists (e.g. rimonabant) for the management of multiple cardiometabolic risk factors. $^{23-25}$

Considering that (1) most patients with type-2 diabetes are overweight or obese and have a high cardiovascular risk, and (2) various organs with a key role in diabetes-related hyperglycaemia contain both EC and CB1 receptors, the role of the EC system and its therapeutic modulation deserve much attention in the pathophysiology and management of type-2 diabetes, respectively. The aim of the present review is to analyse the rationale for use and the potential role of CB1-receptor inhibitors, especially rimonabant, in the management of overweight/obese patients with type-2 diabetes and other cardiometabolic risk factors. 


\section{ROLE OF THE ENDOCANNABINOID SYSTEM AND CB1 RECEPTORS}

\section{The endocannabinoid system}

The term 'endocannabinoid' was coined in the mid-1990s after the discovery of the membrane receptors of the $\delta 9$-tetrahydrocannabinol and its endogenous ligands. Today it describes an entire signalling system comprising CB receptors, endogenous ligands, and enzymes for the synthesis and degradation of ligands.

The EC system first emerged as a major neuromodulatory system in the brain. ${ }^{12,13}$ Within the brain, ECs act as retrograde neurotransmitters (or messengers) that inhibit synaptic activity. ${ }^{15}$ More recently, the EC system has also been shown to be an intercellular signalling system that plays an important role in various peripheral organs, especially those controlling energy metabolism. ${ }^{14}$ Although ECs influence numerous behaviours, in general the net effect of ECs at diverse sites in the brain and throughout the body is anabolic, facilitating increased energy intake, decreased energy expenditure, and increased accumulation of body fat. ${ }^{14,15}$

Two major endogenous ECs, anandamide and 2-arachidonoyl glycerol (2-AG) -derived from membrane phospholipids and triglycerides, respectively - have been identified. ${ }^{26}$ One distinctive feature of ECs is 'usedependent' synthesis. In contrast to classical neurotransmitters, ECs are not stored in vesicles. Instead, they are synthesized on demand in response to acute stimulation. ${ }^{14,16}$ This response is mediated through increased intracellular calcium concentrations. The enzymes most likely responsible for anandamide and 2-AG biosynthesis have been cloned. ECs are released from the cells immediately after their biosynthesis and are capable of binding to and functionally activating specific CB receptors.

Two CB receptors have been identified and molecularly characterized so far: namely, CB1 and CB2 receptors. $^{27,28}$ The ubiquitous $\mathrm{CB} 1$ receptors are found in numerous organs involved in the regulation of energy homeostasis (see below). ${ }^{14} \mathrm{CB} 2$ receptors are present almost exclusively in blood and immune cells.

ECs are rapidly removed from the extracellular space by selective uptake into the cells and intracellular enzymatic hydrolysis. Two enzymes have been shown to play a major role in EC degradation: the fatty acid amide hydroxylase (FAAH) and the monoacylglycerol lipase (MAGL). ${ }^{26,29}$

In general, the EC system is involved in many different physiological functions, many of which relate to stressrecovery systems and to the maintenance of energy balance. In particular, the EC system is regarded as an integrated physiological system modulating nutrient intake, transport, metabolism and storage, the dysfunction of which is associated with abdominal adiposity and its associated co-morbidities. ${ }^{14}$ EC system over-activity may result from increased EC synthesis, $\mathrm{CB}$ receptor over-expression and/or decreased EC degradation. Conversely, pharmacological modulation to correct over-activity of the EC system may theoretically involve reduction of EC production, blockade of CB1 receptors and/or enhancement of EC degradation. ${ }^{16}$

\section{The CB1 receptors}

CB1 receptors, like CB2 receptors, are seven-transmembrane-G-protein-coupled receptors, similar to the receptors for many hormones and neurotransmitters. ${ }^{28} \mathrm{CB} 1$ receptor and tissue concentrations of ECs sufficient to activate them are more widely distributed than originally thought. They are present in all brain and peripheral organs involved in the control of energy homeostasis. In the brain, studies have established that ECs and CB1 receptors mediate food intake both in the hypothalamus, which controls energy homeostasis, and in the limbic system, which controls the pleasure aspects of eating. ${ }^{20,30}$

The demonstration of the expression of CB1 receptors in adipocytes and the ability of a CB1-receptor antagonist (rimonabant) to block lipogenesis stimulated by ECs represented a first important step forward in understanding the peripheral mechanisms of action of the EC system in regulating metabolic processes. ${ }^{22}$ This was confirmed by the demonstration that the blockade of CB1 receptors by rimonabant leads to an increased expression of adiponectin in adipocytes. ${ }^{31}$ Owing to the favourable metabolic and vascular effects recognized for adiponectin ${ }^{32}$, this may at least partially explain various effects such as improvement of insulin sensitivity and oxidation of fatty acids, and reduction in vascular inflammation. ${ }^{31}$ These CB1 receptors are also found in the gut ${ }^{33}$, liver ${ }^{34}$, skeletal muscle $^{35}$, and pancreas ${ }^{36,37}$, all organs playing a key role in the pathophysiology of type-2 diabetes (Figure 1) (see below).

\section{The CB1 -receptor inhibitors}

Pharmacological investigations have placed emphasis on the generation of substances acting as specific agonists or antagonists of CB receptors. ${ }^{17,27}$ The CB1-receptor antagonists known so far are diarylpyrazoles, aminoalkylindoles, or triazole derivatives. There are different possible mechanisms by which CB1-receptor antagonists produce their effects on the CB1 receptor. The ligands can be competitive antagonists of CB1receptor activation by endogenously released ECs (neutral antagonists), or they can act as inverse agonists modulating constitutive CB1-receptor activity by shifting it from an active 'on' to an inactive 'off' state. ${ }^{18,38,39}$ 
Among the increasing number of substances sharing CB1-receptor-antagonist properties, the diarylpyrazole derivative SR141716 (rimonabant) was the first selective one reported ${ }^{40,41}$ and extensively investigated. ${ }^{42,43}$ It is also the only one already commercialized in various countries. In addition to rimonabant, several other CB1receptor antagonists have been synthesized, and many are under development, but at present little is known about them. ${ }^{44}$

\section{Rimonabant}

Rimonabant is a selective CB1-receptor antagonist with little or no affinity for other receptors, including CB2 receptors. ${ }^{40-42}$ Some evidence suggests that rather than acting as a pure (neutral) antagonist, rimonabant might function as an inverse agonist, i.e., it may have intrinsic activity opposite to that of agonists, or it may inhibit constitutive CBI receptor activity. ${ }^{38}$ Rimonabant crosses the blood-brain barrier. It binds extensively $(>99 \%)$ to plasma proteins. However, the potential for drug-drug interactions at this site is small because of the large volume of distribution of the drug. In vitro, rimonabant is metabolized predominantly by hepatic pathways, largely by cytochrome P-450 CYP3A4 and amidohydrolase. Thus, co-administration of CYP3A4 inhibitors or inducers might increase or decrease the blood levels of rimonabant, respectively. In-vitro studies have suggested a low potential for inhibition or induction of CYP450 isoenzymes by rimonabant, with the exception of a possible mild inhibitory effect on CYP2C8. Rimonabant does not inhibit or induce other CYP enzymes or Pglycoprotein (P-gp) in vitro, and this has been confirmed in vivo. ${ }^{45}$

Rimonabant has been investigated in two major clinical programmes: one (STRATUS) for smoking cessation ${ }^{46}$, and the other - Rimonabant in Obesity (RIO) - for obesity and associated cardiometabolic risk. ${ }^{43}$ However, it may also offer other potential therapeutic opportunities which are currently under investigation or will be considered sooner or later in clinical trials. ${ }^{18,47}$ The most impressive data arose from the RIO programme in overweight/obese individuals with or without comorbidities. ${ }^{19,23,43}$ In this clinical research programme, two doses of rimonabant ( $5 \mathrm{mg}$ and $20 \mathrm{mg}$ ) were compared to placebo, but only the dose of $20 \mathrm{mg}$ has been commercialized (see below).

Figure 1. Potential mechanisms of action of rimonabant, a selective cannabinoid type-1 receptor (CB1 R) antagonist, in the improvement of glucose control and other cardiometabolic risk factors in overweight/ obese patients with type-2 diabetes.

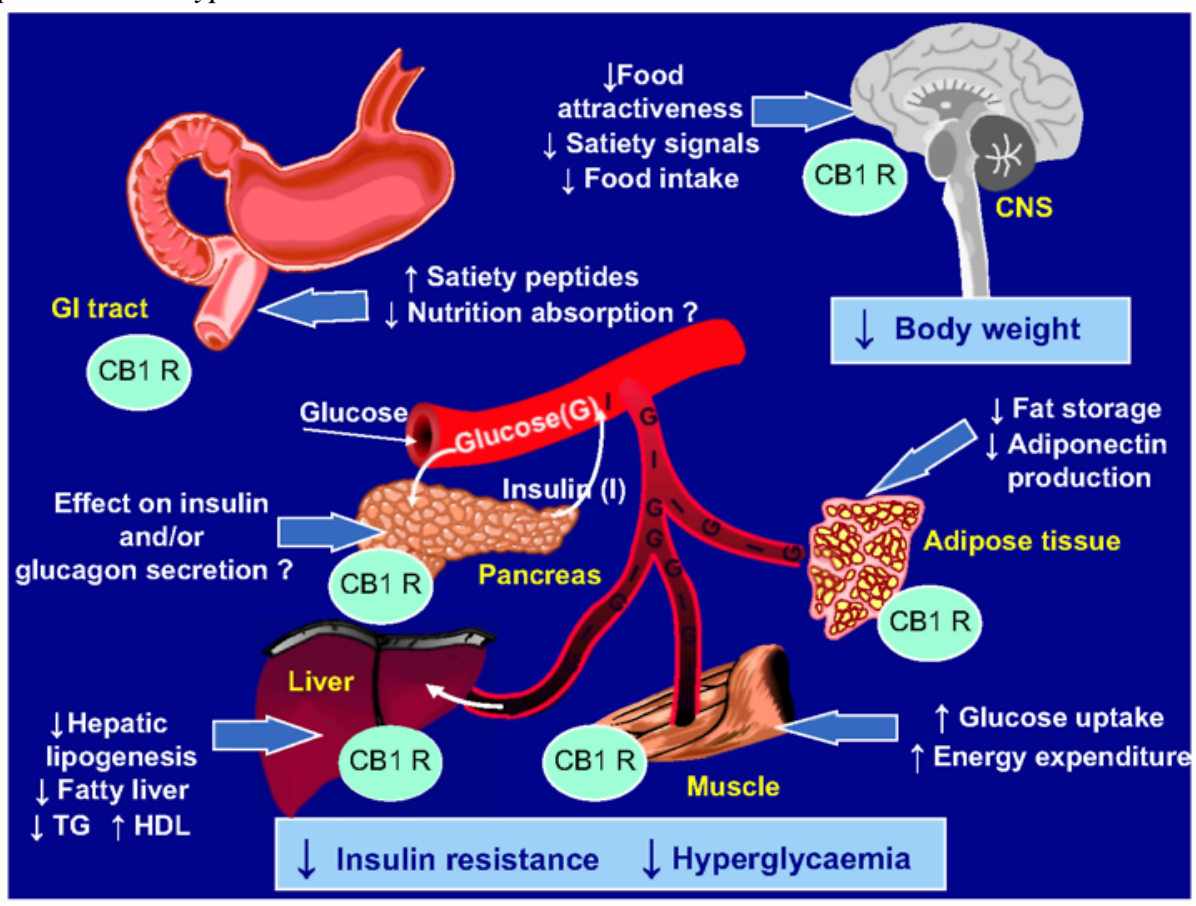




\section{RATIONALE FOR THE USE OF CB1 INHIBITORS IN TYPE-2 DIABETES}

\section{Animal data}

Exogenous CBs and ECs increase food intake and promote weight gain in rodents through activation of central $\mathrm{CB} 1$ receptors. Consistent with the effects of ECs on feeding behaviour are the results of studies with CB1 knockout mice with respect to changes in body weight. $\mathrm{CB} 1^{-/-}$mice are lean and resistant to diet-induced obesity, with no deterioration in insulin sensitivity. ${ }^{14,48}$ Similarly to genetic inactivation of CB1 receptors, pharmacological CB1 antagonism with rimonabant reduced food intake and body weight. ${ }^{49}$ Pair-feeding experiments, however, revealed that the reduced food intake in rimonabant-treated mice was transient and not sufficient to reduce body weight in untreated obese mice. ${ }^{22}$ These surprising findings suggest that body-weight reduction with $\mathrm{CB} 1$ antagonism is only partially explained by a reduction in energy intake, and that energy expenditure may also increase. All of the observations have contributed to the hypothesis that peripheral ECs, and therefore CB1-receptor antagonism in peripheral organs, modulate metabolic regulation independently of food intake. ${ }^{14}$

A considerable amount of evidence suggests that the EC system may regulate food intake by also acting in the gastrointestinal tract. ${ }^{33,50}$ In the liver, ECs promote lipogenesis and steatosis through CB1 receptors. This suggests that ECS activation may contribute to the pathogenesis of non-alcoholic steatohepatitis (NASH), a common feature in overweight/obese patients with type-2 diabetes which is strongly associated with insulin resistance. ${ }^{52,53}$ Furthermore, the fibrotic response of liver was strongly diminished by antagonism or genetic inactivation of $\mathrm{CB} 1$ receptors, suggesting that $\mathrm{CB} 1$-receptor antagonism may represent a new strategy for the treatment of liver fibrosis.

Human adipocytes have been identified as a new source of ECs and related compounds. Treatment of obese mice with CB1-receptor antagonists induced several metabolic events in adipose tissue, such as enhanced lipolysis through stimulation of enzymes involved in $\beta$-oxidation and the tricarboxylic acid cycle, increased energy expenditure through futile cycle induction, and an improvement in glucose uptake through increased expression of glucose transporter 4, a key player in glucose metabolism. ${ }^{56}$ As previously mentioned, adiponectin production is also increased. ${ }^{31}$ Several findings indicate that the EC system participates locally in adipogenesis and fat accumulation, partially by accelerating the appearance and stimulating the activity of peroxisome proliferatoractivated receptor $\gamma(\operatorname{PRAR}-\gamma){ }^{37}$ The precise roles of ECs and CB1 receptors in the skeletal muscle and in the pancreas $^{36,37}$ are less well known and deserve further research - especially in cells and tissues producing and responding to insulin - in order to better understand the role of the EC system in type-2 diabetes.

Despite the fact that, in animals with a well-balanced energy homeostasis, EC levels in the hypothalamus and limbic forebrain are elevated during food deprivation and depressed during food consumption, recent evidence suggests that the EC system, and in particular the levels of either ECs or CB1 receptors or both, become permanently up-regulated in several organs and tissues of obese animals. ${ }^{14,20}$

\section{Human data}

There is increasing evidence in humans for over-activity of the EC system during conditions of unbalanced energy homeostasis - i.e. obesity (especially abdominal obesity) and diabetes - and for its causative role in these disorders. ${ }^{57}$ Preliminary data found that circulating levels of anandamide and 2-AG were significantly increased in obese compared with lean postmenopausal women. ${ }^{58}$ Furthermore, circulating 2-AG was significantly correlated with body fat, visceral fat mass, and fasting plasma insulin concentrations, but negatively correlated with glucose infusion rate during clamp in a group of ten men and ten women. ${ }^{59}$ Obese subjects had a reduction in adipose tissue FAAH gene expression compared with lean individuals ${ }^{58,59}$, and FAAH gene expression was negatively correlated with visceral fat mass and with circulating 2-AG. ${ }^{59}$ Another group also showed higher levels of $2-A G$ in the serum and visceral, but not subcutaneous, fat of obese subjects. In a further study in untreated asymptomatic men, plasma 2-AG levels correlated positively with body mass index (BMI), waist girth, intra-abdominal adiposity, fasting triglycerides and insulin levels, and correlated negatively with HDL-C and adiponectin levels.

However, ECs are not normally released from tissues into the bloodstream to act as hormone-like molecules. Therefore, the findings of elevated levels of circulating EC suggest an up-regulation of EC production and/or reduced EC degradation in peripheral organs during obesity and hyperglycaemia and a 'spill-over' of ECs into the blood. ${ }^{57}$ All together, these findings suggest that intra-abdominal fat accumulation is a critical correlate of peripheral EC system dysregulation and that the EC system may represent a primary target for the treatment of abdominal obesity and associated metabolic changes, including type- 2 diabetes.

There is, as yet, no clear explanation for the mechanisms responsible for hyperactivation of the EC tone in obesity. However, several recent studies seem to point toward a possible role of genetic mutations, although the topic remains controversial and deserves further investigation. A genetic polymorphism of one of the enzymes 
responsible for EC breakdown (FAAH) has been linked with overweight and obesity in both white and black subjects. ${ }^{61}$ A mutation in FAAH was also shown to influence lipid changes after a low-fat diet in obese subjects. ${ }^{62}$ Furthermore, single-nucleotide polymorphisms of the gene encoding CB1 receptor have been shown to be associated with BMI and fat distribution in two independent samples of adult white European men. Further genetic studies are awaited in order to better understand predisposition factors leading to ES-system over-activity and perhaps target individuals with a expected better therapeutic response to CB1-receptor antagonists.

\section{CLINICAL TRIALS WITH RIMONABANT IN OVERWEIGHT/OBESE NON-DIABETIC PATIENTS}

The selective CB1-receptor blocker rimonabant has been carefully evaluated in the phase-III RIO programme. This programme comprised three large placebo-controlled randomized clinical trials (RCTs) in overweight/obese non-diabetic patients: two 2-year RCTs (RIO Europe and RIO North America) ${ }^{64,65}$ and one 1-year RCT (RIO Lipids) specifically devoted to patients with untreated dyslipidaemia. ${ }^{66}$ These three RCTs produced remarkably consistent results (Table 1). After 1 year of follow-up, rimonabant $20 \mathrm{mg}$ was shown to produce significant weight loss $(-4.7$ to $-5.4 \mathrm{~kg})$ and waist circumference reduction $(-3.6$ to $-4.7 \mathrm{~cm})$ as compared to placebo when combined with diet and exercise advice. In addition, improvements in multiple cardiovascular and metabolic risk factors were noticed. In particular, consistent significant reductions in triglyceride levels (-12.4 to $-15.1 \%)$ and increases in HDL-C levels $(+7.2$ to $+8.9 \%)$ were observed in overweight/obese patients treated with rimonabant $20 \mathrm{mg} .{ }^{64,65}$ These improvements persisted after 2 years, with placebo-subtracted differences similar to those after 1 year for changes in body weight, waist circumference, triglycerides and HDL-C (Van Gaal et al, unpublished).

These data were further confirmed in overweight/obese patients with untreated dyslipidaemia, and part of these metabolic improvements could be attributed to a significant increase in plasma adiponectin levels with rimonabant $20 \mathrm{mg} .{ }^{66}$ The levels of low-density lipoprotein (LDL) cholesterol levels were not affected by rimonabant, but the drug was associated with a shift to a lower proportion of small dense LDL particles. ${ }^{66} \mathrm{~A}$ post-hoc analysis demonstrated that the positive effects of rimonabant on atherogenic dyslipidaemia (low HDL$\mathrm{C}$ and high triglycerides) were similar in patients receiving or not receiving cholesterol-lowering therapy with statin. ${ }^{67} \mathrm{~A}$ moderate reduction in systolic and diastolic blood pressure was observed in the rimonabant group as compared to the placebo group, and such a reduction was greater and significant in patients with elevated blood pressure at baseline.$^{68}$ Fasting plasma insulin concentrations and homeostasis model assessment (HOMA) index of insulin resistance were significantly decreased in patients receiving rimonabant $20 \mathrm{mg}$ compared to placebo. The prevalence of the metabolic syndrome as defined with the National Cholesterol Education Program Adult Treatment Panel III (NCEP-ATP III) criteria was significantly reduced in all three trials. Finally, the levels of C-reactive protein were also diminished $(-25 \%)$ in the rimonabant-treated group of the RIO Lipids trial. ${ }^{66}$

To quantify the extent to which improvements in cardiometabolic risk factors are attributable to a direct effect of rimonabant, analyses were performed using pooled data ${ }^{69}$ from patients in RIO Europe ${ }^{64}$, RIO North America ${ }^{67}$, RIO Lipids ${ }^{66}$, and also RIO Diabetes. ${ }^{70}$ Changes from baseline in cardiometabolic variables, namely body weight, lipids, fasting glucose and insulin at year 1 were analysed using analysis of covariance with weight loss as a covariate. Approximately half (45-57\%) of the overall treatment effect in year 1 on HDL-C, triglycerides, fasting insulin and insulin resistance was due to a direct effect not attributable to weight loss. Weight-lossadjusted improvements in all factors were significantly better with rimonabant than placebo $(P<0.001$ for HDL$\mathrm{C}$ and triglycerides, $P<0.02$ for fasting insulin and insulin resistance). These results were supported by analysis using weight-loss category. These findings were confirmed at year 2 in RIO Europe (Van Gaal et al, unpublished) and RIO North America. ${ }^{65}$ These improvements in cardiometabolic risk factors beyond weight loss are possibly due to a direct pharmacological effect of rimonabant in peripheral tissues, in agreement with increasing evidence from animal data (see above).

To determine whether rimonabant improves glucose tolerance in overweight/obese non-diabetic patients, data were pooled from the two studies involving oral glucose tolerance tests (OGTTs) at baseline and 1 year (RIO Lipids and RIO Europe) and 2 years (RIO Europe) (Scheen et al, unpublished). After 1 year, rimonabant $20 \mathrm{mg}$ produced significantly greater reductions than placebo in plasma glucose $(-0.64$ versus $-0.37 \mathrm{mmol} / \mathrm{L}, P<0.01)$ and insulin $(-15.2$ versus $-1.8 \mu \mathrm{lU} / \mathrm{mL}, P<0.001)$ levels at 120 minutes post-OGTT Rimonabant $20 \mathrm{mg}$ also significantly reduced both glucose and insulin area under the plasma concentration-time curve values versus placebo(both $P<0.001$ ). Furthermore, rimonabant $20 \mathrm{mg}$ significantly improved the distribution of glucose tolerance status at 1 year in the pooled intent-to-treat population $(P<0.01)$, with an increased proportion of patients with normal glucose tolerance and a decreased proportion of patients with impaired glucose tolerance or diabetes. Favourable effects on glucose tolerance status persisted after 2 years, despite a weight stabilization from year 1 to year 2. These results demonstrate that rimonabant $20 \mathrm{mg}$ can prevent or reverse progression of glucose intolerance in overweight/obese patients and suggest its potential to prevent type- 2 diabetes. Such a prevention effect is currently being tested in a prospective trial in overweight/obese patients with impaired 
glucose tolerance (the RAPSODI trial, see below). As rimonabant targets a key factor in the pathophysiology of the disease, i.e. abdominal obesity and 'adiposopathy ${ }^{25}$, one may speculate that this effect may be a true preventive effect, rather than a delaying or masking effect as previously reported and discussed with various oral antidiabetic drugs. ${ }^{71}$

Table 1. Baseline characteristics and effects of rimonabant $20 \mathrm{mg}$ (placebo-subtracted differences) on cardiometabolic risk factors in non-diabetic overweight/obese patients.

$\begin{array}{lll}\text { RIO Europe } & \text { RIO North America } & \text { RIO Lipids } \\ (n=1.507) & (n=3.040) & (n=1.033)\end{array}$

Baseline data:

Caucasians (\%)

Sex ratio $(\%$ men $)$

Age (years)

Body weight $(\mathrm{kg})$

BMI $\left(\mathrm{kg} / \mathrm{m}^{2}\right)$

Waist circumference $(\mathrm{cm})$

$\%$ Hypertension

$\%$ Dyslipidaemia

$\%$ Metabolic syndrome

$\begin{array}{lll}93.6 & 84.0 & 96.8 \\ 20.5 & 19.3 & 39.4 \\ 45.0 & 45.0 & 47.8 \\ 101.0 & 104.4 & 94.1 \\ 36.0 & 37.6 & 33.3 \\ 108.4 & 105.8 & 105.0 \\ 40.9 & 30.4 & 27.2 \\ 60.7 & 62.6 & 100 \\ 41.3 & 34.7 & 54.0\end{array}$

Delta versus placebo (ITT, one year):

Body weight $(\mathrm{kg})$

$\begin{array}{lll}-4.7 & -4.7 & -5.4 \\ +31.7 & +28.6 & +38.9 \\ +20.1 & +16.7 & +25.4 \\ -4.2 & -3.6 & -4.7 \\ +8.9 & +7.2 & +8.1 \\ -15.1 & -13.2 & -12.4 \\ -0.11 & -0.04 & -0.02 \\ -2.8 & -2.8 & -2.6 \\ -0.8 & -0.8 & ? \\ -1.2 & -0.2 & -1.7 \\ -1.0 & +0.2 & -1.6\end{array}$

$\%$ Patients with $>5 \%$ weight loss

$\%$ Patients with $>10 \%$ weight loss

Waist circumference $(\mathrm{cm})$

HDL cholesterol (\%)

Triglycerides $(\%)$

Fasting glucose $(\mathrm{mmol} / \mathrm{L})$

Fasting insulin $(\mu \mathrm{U} / \mathrm{mL})$

HOMA-IR

Systolic BP (mmHg)

Diastolic BP (mmHg)

RIO, Rimonabant in Obesity programme; BMI, body mass index; ITT, intention to treat; HDL, high-density lipoprotein; HOMA-IR, homeostasis model assessment index of insulin resistance.

\section{CLINICAL TRIALS WITH RIMONABANT IN TYPE-2 DIABETES}

\section{RIO Diabetes in metformin- or sulphonylurea-treated patients}

The RIO Diabetes trial investigated the efficacy and safety of rimonabant in overweight/obese patients with type-2 diabetes. ${ }^{70}$ In this trial 1047 overweight/obese type-2 diabetes patients (BMI $27-40 \mathrm{~kg} / \mathrm{m}^{2}$ ) with an $\mathrm{HbA} 1 \mathrm{c}$ of $6.5-10.0 \%$ (mean \pm SD $7.3 \pm 0.9 \%$ at baseline) and already on metformin or sulphonylurea monotherapy were given a mild hypocaloric diet and randomized to placebo or rimonabant $(5 \mathrm{or} 20 \mathrm{mg}$ ) for 1 year. The primary endpoint was weight change from baseline after 1 year of treatment. Secondary endpoints included changes in waist circumference and HbA1c, HDL cholesterol, and triglyceride levels (Table 2). Almost two thirds of the diabetic population received metformin as monotherapy, the oral antidiabetic drug considered as first choice in the management of type- 2 diabetes. ${ }^{72}$

Weight loss in the intention-to-treat population was significantly greater after 1 year with rimonabant $20 \mathrm{mg}$ $(-5.3 \pm 5.2 \mathrm{~kg} ; P<0.001)$ than with placebo $(-1.4 \pm 3.6 \mathrm{~kg})$. These weight differences compared favourably with those previously reported with orlistat and sibutramine in overweight/obese patients with type- 2 diabetes. ${ }^{73,74}$ Rimonabant $20 \mathrm{mg}$ improved HbA1c $(-0.6 \pm 0.8 \%$ versus $+0.1 \pm 1.0 \%$ for placebo; $P<0.001)$ in patients with a mean baseline $\mathrm{HbA} 1 \mathrm{c}$ of $7.3 \%$. Treatment with rimonabant $20 \mathrm{mg}$ enabled a greater number of patients to attain the HbA1c American Diabetes Association (ADA) target (HbAlc < 7\%: 67.9\% versus 47.6\% with placebo) and the HbA1c International Diabetes Federation (IDF) target (HbA1c $<6.5 \%: 42.9 \%$ versus 20.8\% with placebo). Improvements were almost similar in patients with type-2 diabetes treated with metformin or sulphonylurea at baseline. In patients with higher HbA1c levels ( $\geq 8 \%$ ) at baseline, reductions of $0.3 \%$ and $1.1 \%$ were observed in the placebo and rimonabant $20 \mathrm{mg}$ treatment groups, respectively $(P=0.001)$. 
Waist circumference, HDL cholesterol, triglycerides, fasting glucose levels, HOMA-estimated insulin resistance, systolic blood pressure, metabolic syndrome prevalence, and C-reactive protein levels also improved significantly with rimonabant $20 \mathrm{mg}$ versus placebo (Table 2). These favourable effects on multiple cardiovascular risk factors are important to improve the overall cardiovascular prognosis in this population. ${ }^{75}$ These results confirm in overweight/obese patients with type-2 diabetes what was previously observed in the non-diabetic population. Again, the $\mathrm{HbA1c}$ and HDL cholesterol improvements with rimonabant $20 \mathrm{mg}$ were approximately twice those expected from the observed weight loss alone. The $0.7 \%$ observed reduction in $\mathrm{HbA1c}$ levels seen with rimonabant $20 \mathrm{mg}$ versus placebo appears to be greater than the corresponding reduction observed with orlistat or sibutramine. ${ }^{73}$ It is clinically relevant since the United Kingdom Prospective Diabetes Study (UKPDS) showed that each $1 \%$ reduction in HbA1c was significantly associated with a reduction in risk of $21 \%$ for any endpoint related to diabetes. ${ }^{76}$

Table 2. Effects of rimonabant in overweight/obese patients with type-2 diabetes: comparison of the results (placebo-subtracted differences) in the 1-year Rimonabant in Obesity (RIO) Diabetes trial and in the 6-month SERENADE trial.

$$
\text { RIO Diabetes }(n=1.045) \quad \text { SERENADE }(n=278)
$$

\begin{tabular}{|c|c|c|}
\hline \multicolumn{3}{|l|}{ Baseline data: } \\
\hline Caucasians $(\%)$ & 88.5 & 84.0 \\
\hline Sex ratio (\% men $)$ & 49.1 & 50.5 \\
\hline Age (years) & 55.6 & 56.6 \\
\hline Body weight (kg) & 96.3 & 96.4 \\
\hline $\operatorname{BMI}\left(\mathrm{kg} / \mathrm{m}^{2}\right)$ & 33.7 & 34.5 \\
\hline Waist circumference $(\mathrm{cm})$ & 109.0 & 108.8 \\
\hline \% Hypertension (*) & 61.2 & 67.3 \\
\hline$\%$ Dyslipidaemia & 55.6 & $?$ \\
\hline$\%$ Metabolic syndrome & 79.3 & $?$ \\
\hline Time since diabetes diagnosis (years) & 5.1 & 1.3 \\
\hline HbAlc $(\%)$ & 7.5 & 7.9 \\
\hline$\%$ on metformin monotherapy & 65 & 0 \\
\hline$\%$ on sulphonylurea monotherapy & 35 & 0 \\
\hline \multicolumn{3}{|l|}{ Delta versus placebo (ITT): } \\
\hline Follow-up (months) & 12 & 6 \\
\hline Body weight $(\mathrm{kg})$ & -3.9 & -3.9 \\
\hline Waist circumference $(\mathrm{cm})$ & -3.3 & -4.0 \\
\hline HbAlc $(\%)$ & -0.7 & -0.51 \\
\hline$\%$ Patients with $\mathrm{HbA} 1 \mathrm{c}<7.0 \%$ & +25.9 & +15.7 \\
\hline$\%$ Patients with $\mathrm{HbA} 1 \mathrm{c}<6.5 \%$ & +22.1 & +7.8 \\
\hline HDL cholesterol (\%) & +8.4 & +7.3 \\
\hline Triglycerides $(\%)$ & -16.4 & -17.3 \\
\hline Glucose $(\mathrm{mmol} / \mathrm{l})$ & -0.97 & -1.00 \\
\hline Insulin $(\mu \mathrm{U} / \mathrm{ml})$ & -I.I & -2.8 \\
\hline Systolic BP (mm Hg) & -2.3 & -1.6 \\
\hline Diastolic BP (mm Hg) & -1.2 & -0.6 \\
\hline HOMA-IR & $?$ & -2.22 \\
\hline
\end{tabular}

BMI, body mass index; ITT, intention to treat; HDL, high-density lipoprotein; HOMA-IR, homeostasis model assessment index of insulin resistance.

\section{SERENADE in drug-naïve patients}

The favourable effects of rimonabant in type-2 diabetes have been recently confirmed in SERENADE (Study Evaluating Rimonabant Efficacy in drug-NAive DiabEtic patients), a 6-month placebo-controlled trial in overweight/obese individuals with recent-onset diabetes treated with diet alone (Table 2). ${ }^{77}$ HbAlc (primary endpoint in this trial) decreased by $0.8 \%$ in the group receiving rimonabant $20 \mathrm{mg}$ compared to $0.3 \%$ in the group receiving placebo $(P=0.0002$; mean baseline HbA1c 7.9\%). These differences were similar to those observed after 6 months in RIO Diabetes. ${ }^{70}$ In patients with higher HbAlc levels $(\geq 8.5 \%)$ at baseline, reductions of $0.7 \%$ and $1.9 \%$ were observed in the placebo and rimonabant $20 \mathrm{mg}$ treatment groups, respectively $(P<0.001)$. Similarly to the changes observed in RIO Diabetes, significant reductions in body weight, waist 
circumference and triglyceride levels were observed, whereas a significant increase in HDL cholesterol was noticed with rimonabant. Rimonabant also decreased the HOMA-IR insulin resistance index and significantly increased plasma adiponectin levels $(+1.8 \mu \mathrm{g} / \mathrm{mL}, P<0.0001$, as had already been reported in the non-diabetic population of RIO Lipids. ${ }^{66}$ Again, almost half of the metabolic improvement occurred beyond weight loss $(57 \%$ for $\mathrm{HbA} 1 \mathrm{C}$ reduction). ${ }^{77}$

\section{OTHER CLINICAL TRIALS WITH RIMONABANT}

\section{Metabolic studies}

In the recent ADAGIO trial, which essentially investigated the effects of rimonabant $20 \mathrm{mg}$ on lipid profile and visceral adipose tissue, diabetes was not an exclusion criterion, and $17 \%$ of the randomized patients had type- 2 diabetes. This study confirmed the positive effect of rimonabant $20 \mathrm{mg}$ on waist reduction and on HDL cholesterol and triglyceride levels, and demonstrated a significant reduction in visceral adipose tissue and liver fat content (J. P. Després, personal communication). This finding is important as far as type-2 diabetes is concerned because fatty liver has been shown to be strongly associated with insulin resistance and profound glucose metabolism dysregulation. ${ }^{78}$

After the demonstration that rimonabant $20 \mathrm{mg}$ is able to improve the glucose tolerance status in overweight/obese patients who were assessed using an OGTT in both the RIO Europe and the RIO Lipids trials (see above; Scheen et al, unpublished), the potential of rimonabant in the prevention of diabetes in overweight/obese patients with impaired glucose tolerance is currently being investigated in the 'RAPSODI' trial.

Finally, the effect of rimonabant $20 \mathrm{mg}$ is being evaluated in several ongoing RCTs specifically devoted to patients with type- 2 diabetes. The ARPEGGIO trial is assessing the effect of rimonabant $20 \mathrm{mg}$ in overweight/obese patients already being treated with exogenous insulin, while in the COMBO trial patients are receiving thiazolidinediones. In all new trials in type- 2 diabetes, HbA1c reduction has been chosen as a primary endpoint. These studies will broaden the spectrum of combined therapy with rimonabant in type-2 diabetes and, if conclusive, may support the role of rimonabant as a possible new antidiabetic agent. ${ }^{25}$

\section{Cardiovascular studies}

As CVD represents by far the greatest cause of mortality in patients with type- 2 diabetes ${ }^{79}$, it is a major objective to reduce the incidence of myocardial infarction and stroke in this high-risk population. ${ }^{1-3,8,9}$ Two imaging studies, including patients with type- 2 diabetes, are currently assessing the effect of rimonabant $20 \mathrm{mg}$ on markers of atherosclerosis: the first one (AUDITOR) focuses on the carotid intima media thickness, and the second one (STRADIVARIUS) uses the coronary intravenous ultrasound (IVUS) technique.

Besides these surrogate endpoints, it is of major interest to demonstrate whether rimonabant is able to improve the overall CVD prognosis in high-risk patients such as those with type-2 diabetes. Weight management ${ }^{7}$, especially correction of abdominal obesity ${ }^{4,5}$, is crucial to obtain a global cardiovascular risk reduction, and previous studies have shown that intentional weight loss is able to reduce overall and CVD mortality in patients with type- 2 diabetes. ${ }^{80}$ The ongoing CRESCENDO (Comprehensive Rimonabant Evaluation Study of Cardiovascular ENDpoints and Outcomes) RCT will assess whether rimonabant $20 \mathrm{mg}$ can reduce the risk of major CVD events in 17,000 abdominally obese patients with clustering risk factors (at least half with type-2 diabetes) followed for 5 years. ${ }^{81}$

\section{SAFETY ISSUES WITH RIMONABANT AND OTHER CB1-RECEPTOR ANTAGONISTS}

The overall safety profile of rimonabant was good in the RIO programme. Adverse events (AEs) most frequently reported with rimonabant were gastrointestinal, neurological and psychiatric in nature, but serious adverse events were infrequent. ${ }^{43}$ Overall AE rates were similar across treatment groups, but discontinuation because of AEs occurred more frequently with rimonabant versus placebo during the first year $(13.6 \%$ versus $7.7 \%$ in the nondiabetic population) (Table 3 ). The most commonly reported AEs were depressive disorders (1.9\% versus $0.8 \%)$, anxiety $(1.0 \%$ versus $0.3 \%)$ and nausea $(1.4 \%$ versus $0.1 \%)$. Most AEs occurred during the first few weeks/months of rimonabant treatment. During the second year, overall discontinuation rate because of AEs was similar (4.7\%) with rimonabant and placebo in a pooled analysis of RIO Europe and RIO North America trials.

In Rio Diabetes, although overall discontinuation rates were similar, discontinuations due to AEs were more frequent in the rimonabant $20 \mathrm{mg}(15.0 \%)$ compared with placebo $(5.5 \%){ }^{70}$ The most common AEs leading to premature study discontinuation in the rimonabant 20-mg group were depressed mood disorders, nausea and dizziness, thus similar AEs as in the non-diabetic overweight/obese population (Table 3 ). However, no serious AEs linked to psychiatric disorders were recorded in the rimonabant 20-mg group. Symptoms of hypoglycaemia 
were uncommon, although slightly more frequent in the rimonabant-treated group than in the placebo group, essentially in diabetic patients receiving sulphonylureas. Overall, the safety profile of rimonabant $20 \mathrm{mg}$ in SERENADE was comparable to that previously reported in RIO Diabetes and in other RIO trials. ${ }^{77}$

The overall safety of rimonabant in the RIO programme has been extensively reviewed. ${ }^{82}$ Finally, the overall safety profile of the drug was assessed recently by the Food and Drug Administration (FDA) which requested additional safety data (see below). ${ }^{83}$

Table 3. Adverse events most commonly causing discontinuation after year 1 in the three Rimonabant in Obesity (RIO) trials in non-diabetic patients (pooled data) and in diabetic patients of RIO Diabetes.

\begin{tabular}{|c|c|c|c|c|}
\hline \multirow{2}{*}{$\begin{array}{c}\text { Number of patients reporting } \\
\text { event }^{\text {a }} \text { (as } \% \text { of total) }\end{array}$} & \multicolumn{2}{|c|}{ Non-diabetic patients } & \multicolumn{2}{|c|}{ Diabetic patients } \\
\hline & $\begin{array}{c}\text { Placebo } \\
(n=1254)\end{array}$ & $\begin{array}{c}\text { Rimonabant } 20 \mathrm{mg} \\
(n=2164)\end{array}$ & $\begin{array}{l}\text { Placebo } \\
(n=348)\end{array}$ & $\begin{array}{c}\text { Rimonabant } 20 \mathrm{mg} \\
(n=339)\end{array}$ \\
\hline $\begin{array}{l}\text { Depressed mood disorders and } \\
\text { disturbances }{ }^{b}\end{array}$ & 1.5 & 2.9 & 0.9 & 3.2 \\
\hline Nausea & $<0.1$ & 1.3 & 0.3 & 1.5 \\
\hline Anxiety & 0.4 & I.I & 0 & 0.6 \\
\hline Dizziness & $<0.1$ & 0.6 & 0 & 0.9 \\
\hline Headache & 0.4 & 0.5 & 0.3 & 0.6 \\
\hline Pregnancy & 0 & 0.5 & 0 & 0 \\
\hline Vomiting & $<0.1$ & 0.2 & 0 & 0.6 \\
\hline Neutropenia & 0.2 & 0.1 & 0 & 0.6 \\
\hline Paraesthesia & 0 & 0.1 & 0 & 0.6 \\
\hline QT interval prolonged & $<0.1$ & $<0.1$ & 0.3 & 0.6 \\
\hline Chest pain & $<0.1$ & $<0.1$ & 0 & 0.6 \\
\hline Peripheral coldness & 0 & 0 & 0 & 0.6 \\
\hline Road traffic accident & 0 & 0 & 0 & 0.6 \\
\hline
\end{tabular}

The reasons for discontinuation of rimonabant in SERENADE were similar to those reported in RIO Diabetes.

${ }^{a}$ Events reported by at least $0.5 \%$ of patients on rimonabant $20 \mathrm{mg}$ in either population.

${ }^{\mathrm{b}}$ Includes preferred terms depression, major depression and depressed mood.

\section{RIMONABANT IN CLINICAL PRACTICE}

Rimonabant (Acomplia ${ }^{\circledR}, 20 \mathrm{mg}$ ), the first of this new class of CB1-receptor antagonists, has been approved by the Committee for Medicinal Products for Human Use of the European Medicines Agency (EMEA) 'as an adjunct to diet and exercise for the treatment of obese patients $(B M I \geq 30 \mathrm{~kg} / \mathrm{m})$, or overweight patients $(\mathrm{BMI}>$ $27 \mathrm{~kg} / \mathrm{m}^{2}$ ) with associated risk factor(s), such as type-2 diabetes or dyslipidaemia'. Furthermore, the Committee recognized that half of the observed improvements in several metabolic parameters $\left(\mathrm{HbA}_{1 \mathrm{c}}, \mathrm{HDL}\right.$ cholesterol and triglycerides) in patients who received $20 \mathrm{mg}$ rimonabant was beyond that expected from weight loss, in agreement with direct peripheral metabolic effects.

However, the Endocrinologic and Metabolic Drugs Advisory Committee of the FDA in a recent review process on June 13, 2007 raised concern about the safety profile of rimonabant (depression, suicidal feelings, neurological adverse events). ${ }^{83}$ Consequently, the Committee members did not believe that rimonabant $20 \mathrm{mg}$ (US name: Zimulti ${ }^{\circledR}$ ) has a favourable risk-benefit profile and should not be approved at the present time for the indication recognized by the EMEA. Sanofi-Aventis will provide additional data in the near future in order to answer all the questions about safety raised by the Committee. This decision will postpone the launch of rimonabant in the United States and most probably will make the clinical development of further CB1-receptor antagonists even more difficult.

Patients most likely to benefit from rimonabant are those with multiple cardiometabolic risk factors known to be improved by the drug, such as abdominal obesity, type-2 diabetes and atherogenic dyslipidaemia (LDL cholesterol and/or high triglycerides). Rimobanant is not a cosmetic drug and is not indicated for patients with a $\mathrm{BMI}<27 \mathrm{~kg} / \mathrm{m}^{2}$ or for those with a BMI between 27 and $29.9 \mathrm{~kg} / \mathrm{m}^{2}$ but who have no associated cardiometabolic risk factor(s). Rimonabant is contraindicated for pregnant or breast-feeding women and is not recommended for children less than 18 years of age. Moreover, it should not be given to patients with severe renal/hepatic impairment. Because patients with prior depression or receiving antidepressants were excluded from the RIO programme, and because mood disorders were more frequently observed with rimonabant than with placebo in all clinical trials, rimonabant is also contraindicated in patients with uncontrolled serious psychiatric illness such as major depression, or patients receiving antidepressant medication. Monitoring for on-treatment anxiety and 
depression will be necessary in the future to ensure the safe use of rimonabant or of any other CB1-receptor antagonist.

\section{CONCLUSIONS}

The discovery of the EC system represents a hallmark not only in neuroscience but also in metabolic research. The exploitation of its numerous physiological and patho-physiological functions is a promising avenue for therapeutic applications. Evidence suggests that CB1-receptor blockade is a novel therapeutic strategy that addresses the underlying mechanisms of both abdominal obesity and cardiometabolic risk, both being strongly associated with type- 2 diabetes.

Even if lifestyle intervention is essential, the potential role of rimonabant in overweight/obese patients with type2 diabetes and a high risk of cardiovascular disease deserves consideration. The results of RIO Diabetes and SERENADE demonstrate the therapeutic value of the CB1-receptor antagonist rimonabant $20 \mathrm{mg}$ in patients with type-2 diabetes; multiple favourable effects comprise effective weight loss, reduced abdominal adiposity, a clinically significant reduction in HbA1c levels, and improvements in HDL-C, triglycerides, C-reactive protein levels, blood pressure, and insulin resistance. Most metabolic improvements - especially the reduction in $\mathrm{HbA} 1 \mathrm{c}$ and the increase in HDL-C levels - were almost twice that expected from the weight loss alone, consistent with direct peripheral metabolic effects of the drug. Safety issues mainly concern mild digestive side-effects and mood disorders, which contraindicate the use of rimonabant in patients with a history of depression or on antidepressants. These findings support the use of rimonabant $20 \mathrm{mg}$ as a new approach to improve glucose control and reduce multiple cardiovascular and metabolic risk factors in overweight/obese patients with type-2 diabetes, in addition to diet and exercise, provided that psychiatric contraindications are respected. Further ongoing studies should confirm the long-term efficacy and safety of rimonabant, the first selective CB1-receptor antagonist, especially in patients with type-2 diabetes.

\section{Practice points}

- rimonabant should be prescribed only in overweight/obese patients whose cardiovascular risk is expected to be greater without rimonabant than the potential psychological risk with rimonabant

- patients with a high cardiometabolic risk in whom lack of intervention is highly deleterious should be selected

- treatment with rimonabant should be continued only in good responders (weight reduction/metabolic

improvement)

- patients with prior depression or receiving antidepressants should be excluded

- treatment with rimonabant should be interrupted in the presence of mood disorders

\section{Research agenda}

- better assessment of the role of CB1 antagonists such as rimonabant on visceral adipose tissue and insulin sensitivity using gold-standard methods

- better evaluation of the metabolic improvement due to direct effects beyond weight reduction

- better identification of individuals who may be good responders in terms of weight reduction and metabolic improvement

- better identification of individuals who may be at risk of developing psychological disorders (anxiety and depression) with rimonabant

- confirmation of the efficacy of rimonabant in diabetic patients already receiving treatment other than metformin or sulphonylurea

- confirmation of the long-term efficacy and safety of rimonabant ( $>1-2$ years), especially in the type-2 diabetic population

- demonstration of the favourable effect of rimonabant on atherosclerotic lesions and on cardiovascular hard endpoints

\section{REFERENCES}

1. Task Force on Diabetes and Cardiovascular Diseases of the European Society of Cardiology (ESC) and the European Society for the Study of Diabetes (EASD). Guidelines on diabetes, prediabetes and cardiovascular diseases: executive summary. European Heart Journal 2007; $28: 88-136$

2. Expert Panel on Detection Evaluation and Treatment of High Blood Cholesterol in Adults. Third report of the National Cholesterol Education Program (NCEP) expert panel on detection, evaluation, and treatment of high blood cholesterol in adults (adult treatment panel iii) final report. Circulation 2002; 106: 3143-3421. 
5Published in: Best practice \& research. Clinical endocrinology \& metabolism (2007), vol. 21, iss. 4, pp. 535-553.

Status: Postprint (Author's version)

3. Klein S, Burke LE, Bray GA et al. Clinical implications of obesity with specific focus on cardiovascular disease: a statement for professionals from the American Heart Association Council on Nutrition, Physical Activity, and Metabolism: endorsed by the American College of Cardiology Foundation. Circulation 2004; 110: 2952-2967.

4. Després JP \& Lemieux I. Abdominal obesity and metabolic syndrome. Nature 2006; 444: 881-887.

5. Van Gaal LF, Mertens IL \& De Block CE. Mechanisms linking obesity with cardiovascular disease. Nature 2006; 444: 875-880.

6. Scheen AJ. Current management strategies for coexisting diabetes mellitus and obesity. Drugs 2003; 63: 1165-1184.

7. Lee M \& Aronne LJ. Weight management for type-2 diabetes mellitus: global cardiovascular risk reduction. American Journal of Cardiology 2007; 99(supplementary): 68B-79B.

8. American Diabetes Association. Clinical Practice Recommendations 2005. Diabetes Care 2005; 28(sup-plementary 1): S1-S79.

9. IDF Clinical Guidelines Task force. Global Guideline for Type-2 Diabetes: recommendations for standard, comprehensive, and minimal care. Diabetic Medicine 2006; 23: 579-593.

10. Anderson JW, Kendall CWC \& Jenkins DJA. Importance of weight management in type 2 diabetes: review with meta-analysis of clinical studies. Journal of the American College of Nutrition 2003; 22: 331-339.

11. Poirier P, Giles TD, Bray GA et al. Obesity and cardiovascular disease: pathophysiology, evaluation, and effect of weight loss. Circulation 2006; 113: 898-918.

12. De Petrocellis L, Cascio MG \& Di Marzo V. The endocannabinoid system: a general view and latest additions. British Journal of Pharmacology 2004; 141: 765-774.

13. Howlett AC, Breivogel CS, Childers SR et al. Cannabinoid physiology and pharmacology: 30 years of progress. Neuropharmacology 2004; 47(supplementary 1): 345-358

*14. Pagotto U, Marsicano G, Cota D et al. The emerging role of the endocannabinoid system in endocrine regulation and energy balance. Endocrine Reviews 2006; 27: 73-100.

15. Piomelli D. The molecular logic of endocannabinoid signalling. Nature Reviews. Neuroscience 2003; 4: 873-884.

*16. Di Marzo V, Bifulco M \& De Petrocellis L. The endocannabinoid system and its therapeutic exploitation. Nature Reviews. Drug Discovery 2004; 3: 771-784.

17. Mendizabal VE \& Adler-Graschinsky E. Cannabinoids as therapeutic agents in cardiovascular disease: a tale of passions and illusions. British Journal of Pharmacology 2007; 151: 427-440.

*18. Xie S, Furjanic MA, Ferrara JJ et al. The endocannabinoid system and rimonabant: a new drug with a novel mechanism of action involving cannabinoid CB1-receptor antagonism - or inverse agonism - as potential obesity treatment and other therapeutic use. Journal of Clinical Pharmacy and Therapeutics 2007; 32: 209-231.

19. Gadde KM \& Allison DB. Cannabinoid-1 receptor antagonist, rimonabant, for management of obesity and related risks. Circulation 2006; 114: 974-984.

20. Di Marzo V \& Matias I. Endocannabinoid control of food intake and energy balance. Nature Neuroscience 2005; 8: 585-589.

21. Carai MA, Colombo G, Maccioni P et al. Efficacy of rimonabant and other cannabinoid CB1 receptor antagonists in reducing food intake and body weight: preclinical and clinical data. CNS Drug Reviews 2006; 12: 91-99.

*22. Cota D, Marsicano G, Tschop M et al. The endogenous cannabinoid system affects energy balance via central orexigenic drive and peripheral lipogenesis. The Journal of Clinical Investigation 2003; 112: 423-431.

23. Gelfand EV \& Cannon CP. Rimonabant: a cannabinoid receptor type 1 blocker for management of multiple cardiometabolic risk factors. Journal of the American College of Cardiology 2006; 47: 1919-1926.

24. Woods AC. Role of endocannabinoid system in regulating cardiovascular and metabolic risk factors. American Journal of Medicine 2007; 120(supplementary 3A): S19-S25.

*25. Lafontan M, Piazza PV \& Girard J. Effects of CB1 antagonist on the control of metabolic functions in obese type 2 diabetic patients Diabetes \& Metabolism 2007; 33: 85-95.

26. Kogan NM \& Mechoulam R. The chemistry of endocannabinoids. Journal of Endocrinological Investigation 2006; 29(supplementary to Ndeg 3): 3-14.

27. Pertwee RG. Pharmacology of cannabinoid CB1 and CB2 receptors. Pharmacology and Therapeutics 1997; 74: 129-180.

28. McAllister SD \& Glass M. $\mathrm{CB}(1)$ and $\mathrm{CB}(2)$ receptor-mediated signaling: a focus on endocannabinoids. Prostaglandins Leukotrienes and Essential Fatty Acids 2002; 66: 161-171.

29. Giuffrida A, Beltramo M \& Piomelli D. Mechanisms of endocannabinoid inactivation: biochemistry and pharmacology. The Journal of Pharmacological and Experimental Therapeutics 2001; 298: 7-14.

30. Harrold JA \& Williams G. The cannabinoid system: A role in both the homeostatic and hedonic control of eating? British Journal of Nutrition 2003; 90: 729-734.

31. Bensaid M, Gary-Bobo M, Esclangon A et al. The cannabinoid CB1 receptor antagonist SR141716 increases Acrp30 mRNA expression in adipose tissue of obese fa/fa rats and in cultured adipocyte cells. Molecular Pharmacology 2003; 63: 908-914.

32. Lihn AS, Pedersen SB \& Richelsen B. Adiponectin: action, regulation and association to insulin sensitivity. Obesity Reviews 2005; 6: $13-21$ 
5Published in: Best practice \& research. Clinical endocrinology \& metabolism (2007), vol. 21, iss. 4, pp. 535-553.

Status: Postprint (Author's version)

33. Massa F, Storr M \& Lutz B. The endocannabinoid system in the physiology and pathophysiology of the gastrointestinal tract. Journal of Molecular Medicine 2005; 83: 944-954.

34. Osei-Hyiaman D, DePetrillo M, Pacher P et al. Endocannabinoid activation at hepatic CB1 receptors stimulates fatty acid synthesis and contributes to diet-induced obesity. The Journal of Clinical Investigation 2005; 115: 1298-1305.

35. Liu YL, Connoley IP, Wilson CA et al. Effects of the cannabinoid CB1 receptor antagonist SR141716 on oxygen consumption and soleus muscle glucose uptake in Lep(ob)/Lep(ob) mice. International Journal of Obesity and Related Metabolic Disorders 2005; 29: 183187.

36. Juan-Pico P, Fuentes E, Bermudez-Silva FJ et al. Cannabinoid receptor regulates $\mathrm{Ca}(2+)$ signals and insulin secretion in pancreatic betacells. Cell Calcium 2006; 39: 155-162.

37. Matias I, Gonthier MP, Orlando P et al. Regulation, function, and dysregulation of endocannabinoids in models of adipose and $\beta$ pancreatic cells and in obesity and hyperglycemia. The Journal of Clinical Endocrinology and Metabolism 2006; 91: 3171-3180.

38. Pertwee RG. Inverse agonism and neutral antagonism at cannabinoid CB1 receptors. Life Sciences 2005; 76: $1307-1324$.

39. Salamone JD, McLaughlin PJ, Sink K et al. Cannabinoid CB1 receptor inverse agonists and neutral antagonists: effects on food intake, food-reinforced behaviour and food aversions. Physiology \& behavior 2007; 91: 383-388.

40. Rinaldi-Carmona M, Barth F, Heulme M et al. SR141716A, a potent and selective antagonist of the brain cannabinoid receptor. FEBS Letters 1994; 350: 240-244.

41. Dutta AK, Sard H, Ryan W et al. The synthesis and pharmacological evaluation of the cannabinoid antagonist SRI4I7I6A. Medicinal Chemistry Research 1994; 5: 54-62.

42. Gelfand EV \& Cannon CP. Rimonabant: a selective blocker of the cannabinoid CB1 receptors for the management of obesity, smoking cessation and cardiometabolic risk factors. Expert Opinion on Investigational Drugs 2006; 15: 307-315.

43. Curioni C \& Andre C. Rimonabant for overweight or obesity. Cochrane Database of Systematic Reviews 2006; 4: CD006162.

44. Lange JH, Coolen HK, van Stuivenberg HH et al. Synthesis, biological properties, and molecular modeling investigations of novel 3,4diarylpyrazolines as potent and selective CB1 cannabinoid receptor antagonists. Journal of Medicinal Chemistry 2004; 47: 627-643.

45. Available from, http://www.emea.eu.int/humandocs/Humans/EPAR/acomplia/acomplia.htm.

46. Cahill K \& Ussher M. Cannabinoid type 1 receptor antagonists (rimonabant) for smoking cessation. Cochrane Database of Systematic Reviews 2007; (3): CD005353

47. Bifulco M, Grimaldi C, Gazzerro P et al. Rimonabant: just an antiobesity drug? Current evidence on its pleiotropic effects. Molecular Pharmacology 2007; 71: 1445-1456.

48. Ravinet Trillou C, Delgorge C, Menet C et al. CB1 cannabinoid receptor knockout in mice leads to leanness, resistance to diet-induced obesity and enhanced leptin sensitivity. International Journal of Obesity and Related Metabolic Disorders 2004; 28 : 640-648.

49. Ravinet Trillou C, Arnone M, Delgorge C et al. Anti-obesity effect of SR141716, a CB1 receptor antagonist, in diet-induced obese mice. American Journal of Physiology. Regulatory, Integrative and Comparative Physiology 2003; 284: R345-R353.

50. Gomez R, Navarro M, Ferrer B et al. A peripheral mechanism for CB1 cannabinoid receptor-dependent modulation of feeding. The Journal of Neuroscience 2002; 22: 9612-9617.

51. Schwabbe RF. Endocannabinoids promote hepatic lipogenesis and steatosis through CB1 receptors. Hepatology 2005; 42: 959-961.

52. Luyckx FH, Scheen AJ \& Lefèbvre PJ. Non-alcoholic steatohepatitis: association with obesity and insulin resistance, and influence of weight loss. Diabetes \& Metabolism 2000; 26: 98-106.

53. Medina J, Fernandez-Salazar LI, Garcia-Buey L et al. Approach to the pathogenesis and treatment of non-alcoholic steatohepatitis. Diabetes Care 2004; 27: 2057-2066.

54. Teixeira-Clerc F, Julien B, Grenard P et al. CB1 cannabinoid receptor antagonism: a new strategy for the treatment of liver fibrosis. Nature Medicine 2006; 12: 671-676.

55. Gonthier MR Hoareau L, Festy F et al. Identification of endocannabinoids and related compounds in human fat cells. Obesity 2007; 15: $837-845$.

56. Jbilo O, Ravinet-Trillou C, Arnone $\mathrm{M}$ et al. The $\mathrm{CB} 1$ receptor antagonist rimonabant reverses the diet-induced obesity phenotype through the regulation of lipolysis and energy balance. FASEB Journal 2005; 19: 1567-1569.

57. Matias I \& Di Marzo V. Endocannabinoids and the control of energy balance. Trends in Endocrinology and Metabolism 2007; 18: 27-

58. Engeli S, Bohnke J, Feldpausch M et al. Activation of the peripheral endocannabinoid system in human obesity. Diabetes 2005; 54 $2838-2843$

59. Bluher M, Engeli S, Kloting N et al. Dysregulation of the peripheral and adipose tissue endocannabinoid system in human abdominal obesity. Diabetes 2006; 55: 3053-3060.

60. Cote M, Matias I, Lemieux I et al. Circulating endocannabinoid levels, abdominal adiposity and related cardiometabolic risk factors in obese men. International Journal of Obesity 2007; 31: 692-699.

61. Sipe J, Waalen J, Gerber A et al. Overweight and obesity associated with a missense polymorphism in fatty acid amide hydrolase (FAAH). International Journal of Obesity 2005; 29: 755-759.

62. Aberle J, Fedderwitz I, Klages N et al. Genetic variation in two proteins of the endocannabinoid system and their influence on body mass index and metabolism under low fat diet. Hormone and Metabolic Research 2007; 39: 395-397. 
63. Russo P, Strazzullo P, Cappuccio FP et al. Genetic variations at the endocannabinoid type 1 receptor gene (CNRI) are associated with obesity phenotypes in men. The Journal of Clinical Endocrinology and Metabolism 2007; 92: 2382-2386.

*64. Van Gaal LF, Rissanen AM, Scheen AJ et al. Effects of the cannabinoid-1 receptor blocker rimonabant on weight reduction and cardiovascular risk factors in overweight patients: 1-year experience from the RIO-Europe study. Lancet 2005; 365: $1389-1397$.

*65. Pi-Sunyer FX, Aronne LJ, Heshmati HM et al. Effect of rimonabant, a cannabinoid-1 receptor blocker, on weight and cardiometabolic risk factors in overweight or obese patients. RIO-North America: a randomized controlled trial. The Journal of the American Medical Association 2006; 295: 761-775.

*66. Després JP, Golay A \& Sjöström L. Rimonabant in Obesity-Lipids Study Group. Effects on metabolic risk factors in overweight patients with dyslipidemia. The New England Journal of Medicne 2005; 353: 2121-2134.

67. Després JP, Van Gaal L, Scheen A et al. Rimonabant improves cardiometabolic risk factors in overweight/ obese patients irrespective of treatment with statins: pooled data from the RIO program (Abstract). Atherosclerosis 2006; 7(supplementary): 329.

68. Ruilope LM, Després JP, Scheen A et al. Effect of rimonabant on blood pressure in overweight/obese patients with/without comorbidities: analysis of pooled Rimonabant In Obesity (RIO) study results. Journal of Hypertension, (in press).

69. Pi-Sunyer F-X, Després J-P, Scheen A et al. Improvement of metabolic effects with rimonabant beyond the effect attributable to weight loss alone: pooled one year data from the RIO (Rimonabant In Obesity and Related Metabolic Disorders) program (Abstract). Journal of the American College of Cardiology 2006; 47(supplementary A): 362-A.

*70. Scheen AJ, Finer N, Hollander P, et al, for the RIO-Diabetes Study Group. Efficacy and tolerability of rimonabant in overweight or obese patients with type 2 diabetes: a randomised controlled study. Lancet 2006; 368: 1660-1672.

71. Scheen AJ. Antidiabetic agents in subjects with mild dysglycaemia: prevention or early treatment of type 2 diabetes? Diabetes \& Metabolism 2007; 33: 3-12.

72. Nathan DM, Buse JB, Davidson MB et al. Management of hyperglycemia in type 2 diabetes: a consensus algorithm for the initiation and adjustment of therapy: a consensus statement from the American Diabetes Association and the European Association for the Study of Diabetes. Diabetes Care 2006; 29: 1963-1972.

73. Norris SL, Zhang X, Avenell A et al. Efficacy of pharmacotherapy for weight loss in adults with type 2 diabetes mellitus: a metaanalysis. Archives of Internal Medicine 2004; 164: 395-404

74. Padwal RS \& Majumdar SR. Drug treatments for obesity: orlistat, sibutramine, and rimonabant. Lancet 2007; 369: 71-77.

75. Gaede P, Vedel P, Larsen N et al. Multifactorial intervention and cardiovascular disease in patients with type 2 diabetes. The New England Journal of Medicine 2003; 348: 383-393.

76. Stratton IM, Adler AI, Neil HA et al. Association of glycaemia with macrovascular and microvascular complications of type 2 diabetes (UKPDS 35): prospective observational study. BMJ (Clinical Research Ed) 2000; 321:405-412.

77. Iranmanesh A, Rosenstock J, Hollander P, SERENADE-Study-Group et al. SERENADE : Rimonabant monotherapy for treatment of multiple cardiometabolic risk factors in treatment-naïve patients with type 2 diabetes (Abstract). Diabetic Medicine 2006; 23(supplementary 4): 230 .

78. Yk-Järvinen H. Fat in the liver and insulin resistance. Annals of Medicine 2005; 37: 347-356

79. Deedwania PC \& Fonseca VA. Diabetes, prediabetes, and cardiovascular risk: shifting the paradigm. American Journal of Medicine 2005; $118: 939-947$.

80. Williamson DF, Thompson TJ, Thun $\mathrm{M}$ et al. Intentional weight loss and mortality among overweight individuals with diabetes. Diabetes Care 2000; 23: 1499-1504.

81. CRESCENDO Comprehensive Rimonabant Evaluation Study of Cardiovascular ENDpoints and Outcomes. Available from: http://wwwclinicaltrials.gov/ct/show/NCT00263042?order = 2. [Accessed February 1, 2007]

*82. Van Gaal L, Pi-Sunyer X, Després JP et al. Efficacy and safety of rimonabant for improvement of multiple cardiometabolic risk factors in overweight/obese patients: pooled 1-year data from the RIO program. Diabetes Care (in press).

83. Food and Drug Administration. Available from: http://www.fda.gov/ohrms/dockets/ac/07/briefing/ 2007-4306b1-00-index.htm. 